\title{
INJURY SURVEILLANCE IN TAEKWONDO AND Judo During PHYSIOTHERAPY COVERAGE OF The SeVenth All Africa Games
}

\author{
ABSTRACT: Objective: To obtain data relating to the incidence \\ of injuries sustained during taekwondo and judo competitions at the \\ 7th All Africa Games. \\ Methods: Prospective recording of injuries sustained by athletes who \\ sought physiotherapy services at the games. Details of type of injury, \\ PHILLIPS JS, BSc'; FRANTZ JM', MSc; \\ AMOSUN SL, PhD'; WEITZ W'

\section{'Department of Physiotherapy, University of the Western Cape} \\ ${ }^{2}$ Sparts Science Institute of South Africa
} injury sites and injury severity were obtained.

Results: Seventy athletes out of 390 participants reported injuries. The overall injury risk ratio was 0.18. Injuries reported were strains/sprains (65,6\%), bruises/contusions (16.1\%) and dislocations or fractures $(12,9 \%)$. The upper limbs were more commonly injured. Of the injuries sustained, approximately $18 \%, 69 \%$ and $13 \%$ were respectively classified as mild, moderate and severe injuries.

Conclusions: The high incidence of moderate to severe injuries highlights the need for injury prevention programs and the presence of medical staff at major tournaments in order to make early diagnosis and appropriate intervention.

\section{KEY WORDS: TAEKWONDO; JUDO; INJURIES, PHYSIOTHERAPY, SURVEILLANCE}

\section{INTRODUCTION}

Taekwondo is a type of fighting system that originated in Korea and that employs kicking, punching and various evasive techniques. Judo on the other hand emphasizes grappling techniques, especially those that upset the opponent's balance, in particular gaining leverage, throws, clothes grabbing, joint locks and strangle holds (Encarta encyclopedia). In 1994, taekwondo, as propagated by the World Taekwondo Federation, was recognized by the International Olympic Committee as a sport to be included in the regular Olympic games starting from 2000 in Sydney, Australia (Pieter and Zemper, 1997a \& b). Judo had already gained Olympic status in 1964.

The All Africa Games is one of the four largest multi-sport events in the

\section{CORRESPONDENCE TO: \\ Mrs JS Phillips \\ Department of Physiotherapy \\ University of the Western Cape \\ Private Bag x 17 \\ Bellville \\ 7535}

Tel: 27219592542

Fax: 27219592804

Email:.jphillips@uwc.ac.za world. In the first All Africa Games held in Brazzaville, Congo in 1965, over 2500 athletes participated in 10 sporting codes in which 30 independent African states were represented. The 7th All Africa Games (AAG) was held in Greater Johannesburg, South Africa, in September 1999, and saw the convergence of approximately 6500 athletes and officials from 52 African countries taking part in 17 sporting codes. The participants in both judo and taekwondo were from 27 African countries.

Injuries seem to be an unavoidable part of any athletic activity and Asian martial arts is no exception (Pieter and Van Ryssegem, 1998). Injuries are especially prevalent in contact sports such as full-contact taekwondo or full-contact karate. However, prospective epidemiological studies on injuries in young athletes' participation in martial sports in general are scarce (Pieter and Zemper, 1997b; Pieter et al, 1998). Despite the popularity of these sports at the Olympic and All Africa Games, little is known about the injury profiles of the athletes competing at these games. Although the martial arts are generally practised in a safe environment, they are reputed to be a high-risk activity (Burks and Salterfield, 1998). The injury rate is reported to compare favourably with other mainstream sports, and martial arts are even considered probably safer than most. In a prospective study to determine the incidence of head and neck injuries in young taekwondo athletes, it was found that contusion was the most frequently occurring injury type for both girls and boys and that the major injury mechanism was receiving a blow (Yamamoto and Kigawa, 1993).

In view of the paucity of data during taekwando and judo competitions, particularly in Africa, the main purpose of this study was to obtain data relating to the incidence and degree of severity of injuries sustained by athletes who took part in taekwondo and judo competitions at the 7th AAG, and sought physiotherapy services provided at the games venues. In addition, the study also aimed at determining the injury risk ratio and the injury rates in terms of athlete exposure.

\section{METHODS}

The medical committee for the game identified different teams of health care professionals to provide medical coverage at various competition venues. There were teams of doctors, physiotherapists, nurses, masseurs and St John's First Aid staff. Medical clinics were set up at the venues where the events took place. 
Injured athletes were initially assessed by medical staff at the ringside or in training areas, and were referred to the medical clinics for additional attention or further referral. Physiotherapists were based in the medical centres at the venues for taekwando and judo, and assessed all referred athletes in order to classify the injuries as mild, moderate or severe.

An injury was defined as any incident occurring during warm-up or competition which required medical attention. Injuries were graded as mild, moderate or severe based on the treatment required and the outcome of the injury (Zemper and Pieter, 1989). Mild injuries required first aid treatment only, such as ice and bandaging, and athletes were able to compete in their next match. Moderate injuries necessitated management such as medication, physiotherapy (e.g. ultrasound, interferential, soft tissue mobilization), immobilization, or required a competitor to miss the next match. Severe injuries required referral to the hospital resulting in prolonged immobilization, effectively ruling the competitor out of the competition for the rest of the games. The match doctor later confirmed injuries assessed and classified by the physiotherapist, and the physiotherapist who assessed the injured athlete completed the data capture sheet.

All matches were single elimination competitions. Injury data were recorded on a data capture sheet that was similar to the one used at the 6th AAG in Zimbabwe. Information gathered included the bio-demographic data of the athlete, and the history, assessment and management of the injury. The overall number of athletes who participated in taekwando and judo was 390 , of which 210 athletes (121 males, 89 females) participated in judo. One hundred and eighty athletes (101 males, 79 females) participated in taekwando.

The injury risk ratio was determined by the number of injured athletes per number of participants. Exposure data for calculating injury rates were gathered from records of bouts actually fought. Each bout consisted of three rounds of three minutes each. Injury rates were calculated from the total number of actual matches fought and the total time (in

TABLE 1. Injury data for taekwando competition

\begin{tabular}{|l|l|}
\hline Number of: & \\
\hline Athletes & 80 \\
\hline Matches/bouts & 179 \\
\hline Athlete-exposures to the possibility of being injured (2 per match) & 358 \\
\hline Reported injuries & 31 \\
\hline Total injury rates Per 1000 athlete-exposures (A-E) & 86.6 \\
\hline
\end{tabular}

TABLE 2. Injury data for judo competition

\begin{tabular}{|l|l|}
\hline Number of: & \\
\hline Athletes & 310 \\
\hline Matches/bouts & 309 \\
Athlete-exposures to the possibility of being injured (2 per match) & 618 \\
\hline Reported injuries & 62 \\
\hline Total injury rates Per 1000 athlete-exposures (A-E) & 100.3 \\
\hline
\end{tabular}

TABLE 3. Types of Injuries sustained ( $n=93$ )

\begin{tabular}{|l|l|l|}
\hline & Judo & Taekwondo \\
\hline Strains/sprains & 45 & 17 \\
\hline Bruises/contusions & 5 & 10 \\
\hline Dislocations/Fractures & 8 & 4 \\
\hline Others & 4 & 0 \\
\hline
\end{tabular}

TABLE 4. Distribution of injuries by body part ( $n=93$ )

\begin{tabular}{|l|l|l|l|l|}
\hline Sport & Upper Limb & Lower Limb & Trunk & Head \\
\hline Judo & $32(51.6 \%)$ & $19(30.6 \%)$ & $9(14.5 \%)$ & $2(3.2 \%)$ \\
\hline Taekwondo & $10(32.3 \%)$ & $19(61.3 \%)$ & $1(3.2 \%)$ & $1(3.2 \%)$ \\
\hline
\end{tabular}

minutes) for which athletes were exposed to the possibility of sustaining an injury (Zemper and Pieter, 1989), using the formula: (number of injuries/ number of athlete-exposures) $x 1000$ $=$ number of injuries per 1000 minutes of exposure. One athlete-exposure (A-E) referred to one individual competing in one bout where he/she was exposed to the possibility of being injured. Because there are always two people competing in any one bout, there are two A-Es per bout.

\section{RESULTS}

Seventy athletes were injured in taekwondo and judo events ( $\mathrm{N}=390)$, giving an overall risk ratio of 0.18 . Judo accounted for 43 injured athletes and taekwondo accounted for 27 injured athletes. The injury risk ratios for judo and taekwondo were 0.2 and 0.15 respectively. The summaries of the exposure and injury rates data for taekwando and judo are presented in Tables 1 and 2 respectively.

During the tournament, a total of 93 injuries were reported of which judo accounted for 62 injuries and taekwondo 31 injuries. The injuries sustained included strains and sprains (65.6\%), bruises and contusions (16.1\%), dislocations $(7.5 \%)$ and fractures $5.4 \%$ (Table 3). The distribution of injuries by body part is presented in Table 4 . These areas were further classified into the following regions: shoulder (17\%), hand $(17 \%)$, wrist $(10.7 \%)$, ankle 
(10.8\%), lower leg (10.8\%), trunk $(10.8 \%)$, knee $(7.5 \%)$, foot $(1.2 \%)$ and head $(3.2 \%)$. Injuries to other parts such as elbow and forearm, accounted for $11 \%$. Of the injuries sustained, $18.1 \%$ was classified as mild, $69 \%$ as moderate and $12.9 \%$ as severe injuries.

\section{DISCUSSION}

When large numbers of athletes compete intensely over a short period of time, a variety of injuries are often encountered. Thus, safety in sport has become an issue of concern as injuries seem to be an unavoidable part of any athletic activity, and Asian martial sports are no exception. The cost of injuries to individuals is significant. It becomes increasingly significant when the individual participates at national and international levels, as it affects not only the individual but the team and the country. Unfortunately, no information is available regarding injuries in martial arts in South Africa.

The overall injury risk ratio for this study was 0.18 . This was similar to studies of other sports such as athletics that indicated an injury risk ratio of 0.22 during competition (Bennell and Crossley, 1996). This supports the opinion that the injury rate in martial arts compares favourably with other sports. However with the logistical set up at the games' venues, it was possible that there were some injured athletes who did not report to the medical center to receive physiotherapy. Some of the participating countries came with team physiotherapists who had the sole responsibility of treating their athletes. In addition, there were few cases which the match doctors considered very severe, and were referred directly to nearby hospitals. Therefore there is a possibility that the injury risk ratio could be higher than 0.18 .

In addition, Zemper and Pieter (1989) reported that about $60 \%$ of martial arts injuries sustained during competition are not reported. This was due to (i) athletes considering injuries to be minor, (ii) athletes thinking that they were indispensable, and (iii) the instructor/coach refusing to accept that the athlete was injured. If similar reasons for not reporting injuries at competition were prevalent during the 7th All Africa Games, the injury risk ratio could be higher than what has been reported. However, the total injury rate reported for taekwando in this study (86.6/1000 athlete-exposure) compares favourably with the rates reported by Pieter and Zemper (1997c) for junior athletes (95.1/1000 athlete-exposure) and senior athletes (105.5/1000 athleteexposure). Unfortunately, similar comparison was not possible for judo.

Injuries sustained at the 7th All Africa Games included strains and sprains, bruises and contusions, and fractures and dislocations. The most frequently occurring types of injury were strains and sprains. This was in contrast to earlier studies in which contusions were identified as the most frequently occurring injury types (Zemper and Pieter, 1989; Yamamoto and Kigawa, 1993).

Approximately $13 \%$ of the injuries sustained were dislocations and fractures. This supports the need for injury prevention programmes and the importance of protective gear. The high incidence of closed soft tissue injuries (65.6\%) highlights the need to have medical staff at major tournaments in order to establish an early diagnosis, with the intention of preventing further injury. Early intervention to treat inflammation, pain and limited range of motion will ensure that the athlete can return to competition as soon as possible (Seto and Brewster, 1993). The need for injury prevention programmes is further highlighted by the large percentage of moderate to severe injuries reported in the study. They are referred to as timeloss injuries (Pieter and Zemper, 1997b) since injured athletes are prevented from continuing with ongoing bouts and/or subsequent bouts, and prevented from returning to practice or competition for at least one day.

\section{CONCLUSION}

This study identified that most of the injuries sustained in taekwondo and judo during the 7 th AAG were moderate to severe $(82 \%)$. This justifies the need for availability of medical services at sporting events involving martial arts. The high incidence of injuries sustained during the games, if not controlled, may adversely affect the development of martial arts in Africa.

\section{REFERENCES}

Burks J.B, Salterfield K 1998 Foot and ankle injuries among martial artists. Results of a survey. Joumal American Podiatric Medical Association 88: 268-278

Bennell K, Crossley K 1996 Musculoskeletal Injuries in Track and Field: Incidence, Distribution and Risk Factors. Australian Journal of Science and Medicine in Sport 28: 69-75

Encarta encyclopedia 2000 Internet site: http://www.k-lusa.com/html/link 9 . htm; accessed January 2000

Pieter W, Bercades L.T, Heijmans J 1998 Competition injuries in Olympic taekwondo. Kinesiology 30: 22-30

Pieter W, Van Ryssegem G 1998 Serious injuries in karate and taekwondo. Journal of Asian Martial Arts 7: 10-26

Pieter W, Zemper E.D 1997a Head and neck injuries in adult taekwondo athletes. Coaching and Sport Science Journal 2: 7-12

Pieter W, Zemper E.D 1997b Time-loss injuries in Junior Olympic taekwondo athletes. Sports Exercise and Injury 3: 37-42

Pieter W, Zemper E.D 1997c Injury rates in children participating in taekwando competition. Journal of Trauma: Injury, Infection, and Critical Care 43: 89-96

Seto J, Brewster C 1993 Treatment approaches following foot and ankle injury. Clinics in Sports Medicine 13: 695

Yamamoto T, Kigawa A 1993 Effectiveness of functional ankle taping for judo athletes: a comparison between judo bandaging and taping. British Journal of Sports Medicine 27 II $0-112$

Zemper E.D, Pieter W 1989 Injury rates during the 1988 US Olympic Team Trials for taekwondo. British Journal of Sports Medicine 23: 161-164 